\title{
INHIBITORY EFFECTS OF FOUR NEONICOTINOID ACTIVE INGREDIENTS ON ACETYLCHOLINE ESTERASE ACTIVITY
}

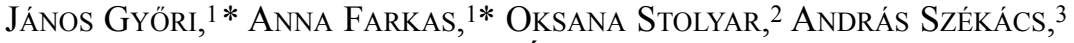 \\ MÁria MÖrtL ${ }^{3}$ and ÁgNes VehovsZKKY ${ }^{1 * *}$ \\ ${ }^{1}$ Department of Experimental Zoology, MTA Centre for Ecological Research, \\ Balaton Limnological Institute, H-8237 Tihany, POB 35, Hungary \\ ${ }^{2}$ Research Laboratory of Comparative Biochemistry and Molecular Biology, \\ Ternopil National Pedagogical University, M. Kryvonosa Str., 2, Ternopil, 46027, Ukraine \\ ${ }^{3}$ Department of Environmental Analysis, Agro-Environmental Research Institute, \\ National Agricultural Research and Innovation Centre, H-1022 Budapest, Herman O. u. 15, Hungary
}

(Received: June 12, 2017; accepted: August 7, 2017)

\begin{abstract}
There is a great concern about the decline of pollinators, and neonicotinoids emerging bee disorders are assumed to play a significant role. Since changes in learning ability has been observed in honey bees exposed to some acetylcholine esterase (AChE) inhibitors, we therefore, tested in vitro the effect of four neonicotinoids on purified eel $\mathrm{AChE}$. AChE activity was inhibited in a concentration-dependent manner, and calculated $\mathrm{IC}_{50}$ values for thiamethoxam $\left(\mathrm{IC}_{50}=414 \mu \mathrm{M}\right)$ and clothianidin $\left(\mathrm{IC}_{50}=160 \mu \mathrm{M}\right)$ were found to be much higher compared to acetamiprid $\left(\mathrm{IC}_{50}=75.2 \mu \mathrm{M}\right)$ and thiacloprid $\left(\mathrm{IC}_{50}=87.8 \mu \mathrm{M}\right)$. The Lineweaver-Burk reciprocal plots for acetamiprid shows unchanged $V_{\max }$ and increased $K_{\mathrm{m}}$ values with inhibitor concentrations, while analysis of Michaelis-Menten plots shows predominantly competitive mechanism. The inhibition constant value $\left(K_{\mathrm{i}}=24.3 \mu \mathrm{M}\right)$ indicates strong binding of the acetamiprid complex to AChE. Finally, the four tested neonicotinoids are not a uniform group regarding their blocking ability. Our results suggest a previously not established, direct AChE blocking mechanism of neonicotinoids tested, thus the neuronal $\mathrm{AChE}$ enzyme is likely among the direct targets of the neonicotinoid insecticides. We conclude, that these AChE inhibitory effects may also contribute to toxic effects on the whole exposed animal.
\end{abstract}

Keywords: Neonicotinoids - acetamiprid - clothianidin - thiamethoxam - in vitro acetylcholinesterase assay

\section{INTRODUCTION}

Neonicotinoids, introduced into the market from 1991, are considered among the most important classes of pesticide active ingredients currently used in agricultural crop protection [5]. Upon the gradual withdrawal of other main classes of insecticides (organophosphates, certain carbamates, pyrethroids, etc.), these selective neurotoxins have become the most widely used ones, covering $25-30 \%$ of the total

* The authors contributed equally in this work.

**Corresponding author; e-mail address:vehovszky.agnes@okologia.mta.hu

Abbreviations: ACh: acetylcholine, AChE: acetylcholine esterase, ACT: acetamiprid, ATChI: acetylthiocholine iodide, CCD: Colony Collapse Disorder, CLO: clothianidin, DTNB: 5,5'-dithiobis(2-nitrobenzoic acid), nAChRs: nicotinic acetylcholine receptors, TIA: thiacloprid, TMX: thiamethoxam 
insecticide market [14]. Neonicotinoids mimic the action of acetylcholine (ACh), one of the main excitatory neurotransmitters of the central nervous system [18]. The primary mechanism of action is their strong binding to the postsynaptic nicotinic acetylcholine receptors (nAChRs) of the insect brain [26], showing more selective pharmacological/toxicological profile to arthropod than vertebrate receptors [25]. The environmental safety of neonicotinoids and their metabolites is of concern because low concentrations of these insecticides are widely distributed in the ecosystem showing pronounced environmental persistence [27], and continuous use of high amounts of neonicotinoids. All these resulted in a significant chemical pressure on the environment [12]. Soil, water, sediments are potentially all contaminated by neonicotinoids and their metabolites, due to their high water solubility and persistency $[1,7,17,23]$.

There is a great concern about the decline of pollinators (including bees), due to so called Colony Collapse Disorder (CCD). This is a worldwide described phenomenon which is characterised by unusual symptoms, including rapid loss of adult worker bees [28]. The role of neonicotinoids in pollinator decline and emerging bee disorders is assumed to play a significant effect [3, 27]. Up to now, seven neonicotinoid active ingredients have been marketed, among them are cyano-substituted ACT, TIA and a member of a second-generation, nitro-substituted class TMX and CLO, the active metabolite of thiamethoxam. CLO has even stronger effect in the insect than TMX. Concerns have been raised in European Union that led to the restriction of neonicotinoid applications particularly as seed treatment containing imidacloprid, TMX or CLO. Due to new regulations, higher purchase of other ingredients (e.g. acetamiprid) is expected. TMX applied topically is very toxic to honeybee, with contact $\mathrm{LD}_{50}$ value of $30 \mathrm{ng} / \mathrm{bee}$, while ACT shows modest activity, being almost three orders of magnitude less toxic $\left(\mathrm{LD}_{50}=7.1 \mu \mathrm{g} / \mathrm{bee}\right)$ than those containing a nitro group [13]. However, behavior and physiology of bees are affected more by ACT than by TMX after acute sublethal treatment $(0.1-1 \mu \mathrm{g} / \mathrm{bee})$ with these active ingredients. Indeed, in contrary to ACT, TMX (0.1-10 ng/bee) induced no significant effect either on locomotor activity and on olfactory learning and memory, both tested in the $\mathrm{LD}_{50} / 100$ to $\mathrm{LD}_{50} / 50$ range more [8].

Very recently evaluation of $\mathrm{AChE}$ activity as a potential biomarker of exposure of neonicotinoids was suggested. Based on field and laboratory studies, an altered $\mathrm{AChE}$ activity in bees was measured in both cases [4]. However, direct link between the neonicotinoid treatment and AChE activity modulation is still lacking, as no data on the possible molecular target of the toxic effects is available. Neonicotinoids generally impair the ACh neurotransmitter related neuronal functions by its agonist (AChlike) effects [18], while AChE by hydrolizing the released ACh regulates the turnover of ACh in the synaptic cleft. At the moment, it is not clear, whether the neonicotinoids directly modulate the AChE enzyme or there are some compensatory mechanisms involved which affect ACh metabolism and finally alter AChE activity.

To test the possible direct involvement of neonicotinoids on AChE activity we applied in vitro experiments using purified eel AChE to determine whether or not cyano- substituted (ACT, TIA), and nitro substituted forms (CLO, TMX) are effective 
blockers of the ACh. The results of these studies may provide a further possibility to characterize the effects of neonicotinoids at both cellular and molecular level. The final aim of our study was to test whether or not the AChE activity could be used as an in vitro marker for monitoring effects associated with neonicotinoids.

\section{MATERIALS AND METHODS}

The individual insecticides we tested were used in the form of the commercially available products in Hungary. Acetamiprid (Mospilan, Sumi Agro), thiamethoxam (Actara, Syngenta), clothianidin (Apacs, Arysta Life Science) and thiacloprid (Calypso, Bayer). The actual concentration of active ingredients was measured by HPLC/UV chromatography. All chemicals including the purified AChE obtained from electric eel (Electrophorus electricus) (type V-S), were obtained from SigmaAldrich Chemie GmbH (Germany).

\section{Acetylcholinesterase inhibition}

Acetylcholinesterase inhibitory activity of complexes was evaluated by the method of Ellman [9] using purified AChE obtained from electric eel (Electrophorus electricus) (type V-S) and ATChI as substrate. The experiments were modified to 96-well microplate format (Victor ${ }^{3}$ plate reader, Perkin-Elmer). Stock solutions of tested complexes were prepared in water, subsequently diluted with phosphate buffer of $\mathrm{pH}$ 7.4. The reaction took place in a final volume of $280 \mu \mathrm{l}$ of $0.1 \mathrm{M}$ phosphate-buffered solution, containing $50 \mu \mathrm{l} \mathrm{AChE}(0.3 \mathrm{U} / \mathrm{ml}$ in $10 \mathrm{mM}$ phosphate buffer of $\mathrm{pH} 7.4)$, $200 \mu \mathrm{l}$ of a $0.3 \mathrm{mM}$ solution of DTNB in $10 \mathrm{mM}$ phosphate buffer containing $6 \mathrm{mM}$ $\mathrm{NaHCO}_{3}$, and $10 \mu \mathrm{l}$ of stock solution of ACT, CLO, TIA or TMX (ten to twelve concentrations ranging from final concentration of $1 \mu \mathrm{M}$ to $1 \mathrm{mM}$ ). After $10 \mathrm{~min}$ incubation period at room temperature $\left(23^{\circ} \mathrm{C}\right), 20 \mu \mathrm{l}$ of stock ATChI $(7.5 \mathrm{mM}$ aqueous solution) was added. Hydrolysis of substrate was followed by measuring the variation of the absorbance in wells at $405 \mathrm{~nm}$ for $15 \mathrm{~min}$. Initial velocity values were calculated by linear regression of the response - time curve. The iteration algorithms of Levenberg-Marquardt were used in all cases. Self-hydrolysis of substrate was verified by running a blank containing no inhibitor and no enzyme in the reaction mixture. Inhibitor controls were also run separately under the same conditions to eliminate inhibitor contribution in the readings. $\mathrm{IC}_{50}$ values, i.e. inhibitor concentrations that reduce enzyme activity by $50 \%$ were calculated by nonlinear regression of the response-log (concentration) curve. Curve fittings were made by Origin Pro 9 software, using built-in dose response fitting function. Data were expressed as the mean $\pm \mathrm{SD}$ of at least three different experiments in triplicates. 


\section{Kinetic analysis of AChE inhibition}

Kinetic assays of AChE were carried in 96-well microtitre plates (SpectraPlate, PerkinElmer). Four different final concentrations of substrate (ACThI) were injected using Wallac 1420 dispenser (Perkin-Elmer). 10-40 $\mu$ substrate (stock solution of $3.75 \mathrm{mM}$ ) was dissolved in phosphate buffer, $\mathrm{pH} 7.4$, containing 160-200 $\mu \mathrm{l}$ of $\mathrm{DTNB}$, and $50 \mu \mathrm{l} \mathrm{AChE}$, respectively, to obtain a final desired volume. One of the tested compound (ACT) was added into the assay solution and pre-incubated with the enzyme at room temperature for $2.5 \mathrm{~min}$, followed by the addition of the substrate. Characterization of the hydrolysis of ATChI catalyzed by AChE was monitored spectrophotometrically at $405 \mathrm{~nm}$ by Victor ${ }^{3}$ plate reader (Perkin-Elmer). Parallel control experiments were carried out without inhibitor in the mixture. To obtain estimates of mechanism of action of these compound plots of initial velocity as a function of substrate concentration for $\mathrm{AChE}$ were constructed at four substrate concentrations $(0.134-0.536 \mu \mathrm{M})$. The plots were assessed by nonlinear regression to determine: $V_{\max }$ (the maximum enzyme velocity), $K_{\mathrm{m}}$ (Michaelis-Menten constant, the substrate concentration yielding a half-maximal velocity), $\alpha$ (determines the mechanism), and $K_{\mathrm{i}}$ (inhibition constant).

Curve fittings and statistical analysis were performed using Origin Pro 9 software, using non-linear fitting algorithms, and Student's $t$-test for testing significance.

\section{RESULTS}

\section{Inhibition studies}

Four neonicotinoids, namely CLO, TIA, TMX, and ACT were tested first by standard $\mathrm{AChE}$ assay procedure (Ellmann reaction adapted to microplate technique) to assess their potential AChE inhibitory effect (Fig. 1). A significant change in affinity to $\mathrm{AChE}$ was found in the presence of neonicotinoids: all insecticides inhibited AChE activity (ACT: $1 \mu \mathrm{M}^{-1} \mathrm{mM}$, CLO: $10 \mu \mathrm{M} 1 \mathrm{mM}$, TIA: $1 \mu \mathrm{M}^{-1} \mathrm{mM}$, TMX: $100 \mu \mathrm{M}^{-1}$ $\mathrm{mM}$ ) in a concentration dependent manner. Fig. 2A shows time dependent increase of absorbance during the assay in the presence of TMX, in the concentration range between $100 \mu \mathrm{M}$ and $1 \mathrm{mM}$. The threshold concentration of TMX was found to be $100 \mu \mathrm{M}$. Solid lines represent the fitting resulted by least-squares analysis. Fig. 2B shows dependence of blocking of AChE activity in the presence of different CLO and TMX concentrations. Non-linear fitting of the dose-response curve yielded in the concentration of inhibitor producing 50\% inhibition under standard conditions. Our calculated $\mathrm{IC}_{50}$ values for TMX $\left(\mathrm{IC}_{50}=414 \mu \mathrm{M}\right)$ occurred to be much higher, while CLO inhibited AChE with a lower $\mathrm{IC}_{50}$ value $(160 \mu \mathrm{M})$. Fig. $3 \mathrm{~A}-3 \mathrm{~B}$ show dependence of blocking of AChE activity in the presence of different ACT $\left(1 \mu \mathrm{M}^{-1}\right.$ $\mathrm{mM})$ and TIA $\left(1 \mu \mathrm{M}^{-1} \mathrm{mM}\right)$ concentrations Comparing the potency of the four tested neonicotinoids, therefore, both threshold and $\mathrm{IC}_{50}$ values showed about a magnitude 
<smiles>CC(=NC#N)N(C)Cc1ccc(Cl)nc1</smiles>

ACETAMIPRID<smiles>CN/C(=N\[N+](=O)[O-])NCc1cnc(Cl)s1</smiles>

CLOTHIANIDIN<smiles>N#CN=C1SCCN1Cc1ccc(Cl)nc1</smiles>

THIACLOPRID<smiles>CN1COCN(Cc2cnc(Cl)s2)/C1=N/[N+](=O)[O-]</smiles>

THIAMETHOXAM

Fig. 1. Chemical structures of the active ingredients of the neonicotinoid insecticides used in the experiments: acetamiprid, ACT (N-[(6-chloro-3-pyridyl)methyl]-N'-cyano-N-methyl-acetamidine), thiacloprid, TIA \{(2Z)-3-[(6-Chloropyridin-3-yl)methyl]-1,3-thiazolidin-2-ylidene $\}$ cyanamide, clothianidin, CLO 1-[(2-Chloro-1,3-thiazol-5-yl)methyl]-2-methyl-3-nitroguanidine and thiamethoxam, TMX

(3-[(2-chloro-1,3-thiazol-5-yl)methyl]-5-methyl- $N$-nitro-1,3,5-oxadiazinan-4-imine)

Table 1

The Hill values and the potency of the four tested neonicotinoids, data based on non linear regression of $\mathrm{IC}_{50}$ curves

\begin{tabular}{|l|c|c|c|c|}
\hline & Acetamiprid & Thiacloprid & Clothianidin & Thiamethoxam \\
\hline Hill Slope & 1.396 & 1.217 & 1.052 & 1.665 \\
\hline $95 \%$ conf. intervals & $1.012-1.780$ & $1.065-1.368$ & $0.904-1.2$ & $0.7731-2.557$ \\
\hline $\mathrm{IC}_{50}(\mathrm{M})$ & $7.520 \mathrm{E}-5$ & $8.782 \mathrm{E}-5$ & 0.00016 & 0.000414 \\
\hline $\mathrm{R}^{2}$ & 0.9807 & 0.9836 & 0.9802 & 0.9841 \\
\hline
\end{tabular}

higher AChE inhibitor effectivity of ACT and TIA to TMX, suggesting the importance of the cyano substitution to improve the inhibitory potency (Table 1).

\section{Kinetic analysis}

The higher efficacy of ACT as AChE inhibitor allowed us to carry out a more detailed kinetic analysis of ACT binding, which may suggest the mechanism of action behind. Thus, binding of complexes with AChE was studied (measuring AChE activity from electric eel in the presence of different concentrations of substrate) in a microplate reader. A kinetic assay of AChE inhibition by ACT between $0.134-0.536 \mathrm{mM}$ substrate concentrations is shown in Fig. 4A. The analysis of Lineweaver-Burk reciprocal plots for ACT (Fig. 4B) shows all identical $V_{\max }$ and increased $K_{\mathrm{m}}$ with $83 \mu \mathrm{M}$ 


\section{A}

\section{$[\mathrm{TMX}]$}
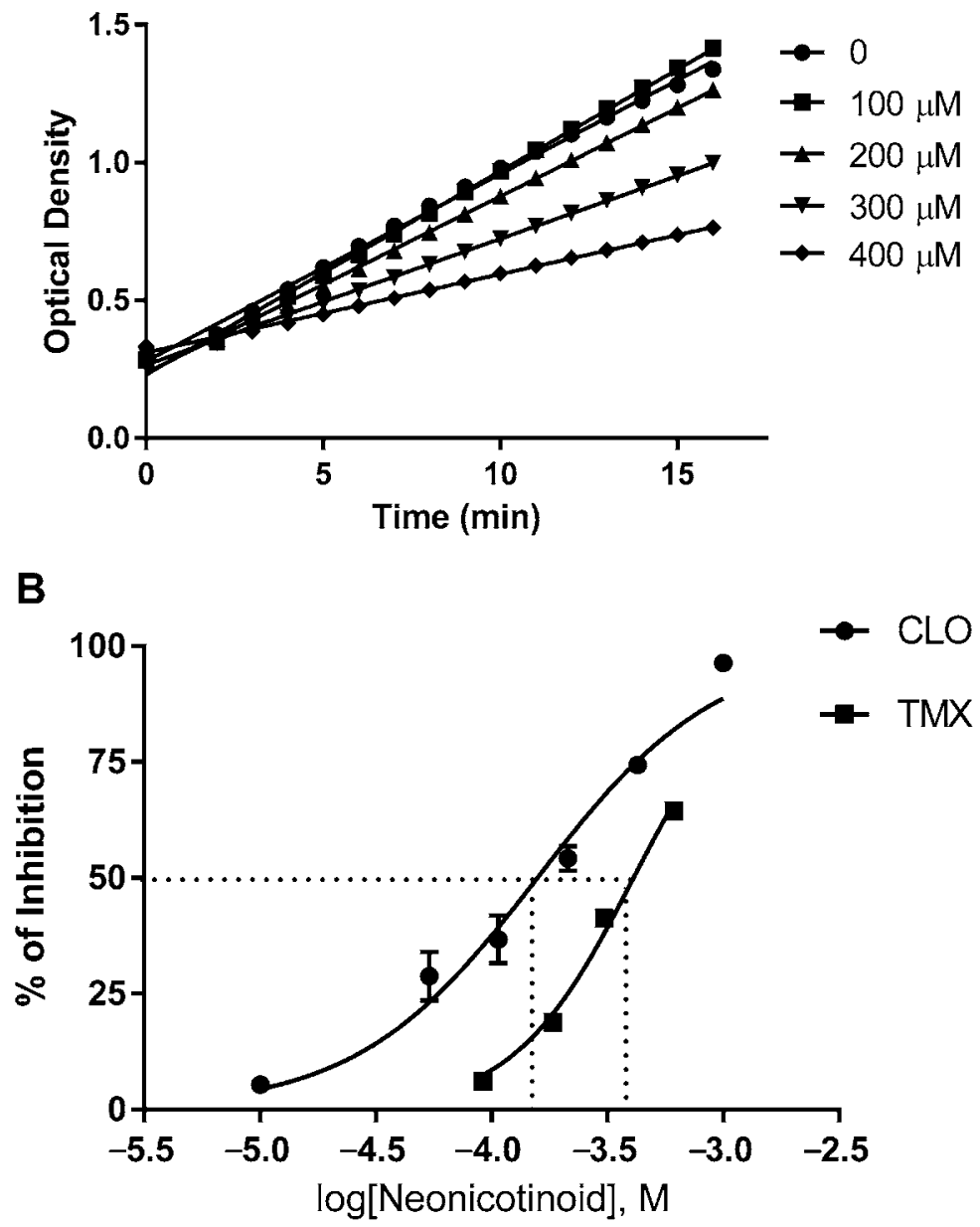

Fig. 2. In vitro inhibition procedure of AChE activity of electric eel using CLO and TMX. A - Time dependence of the AChE activity measured at $405 \mathrm{~nm}$ in the presence of 4 different concentrations of TMX, original traces. Initial velocity values were calculated by linear regression. Solid lines show the results of linear fitting. B - Inhibition of AChE by CLO and TMX, showing the relative enzyme activity as a function of the inhibitor concentration. $\mathrm{IC}_{50}$ curves against inhibitor concentrations of TMX and CLO 
A

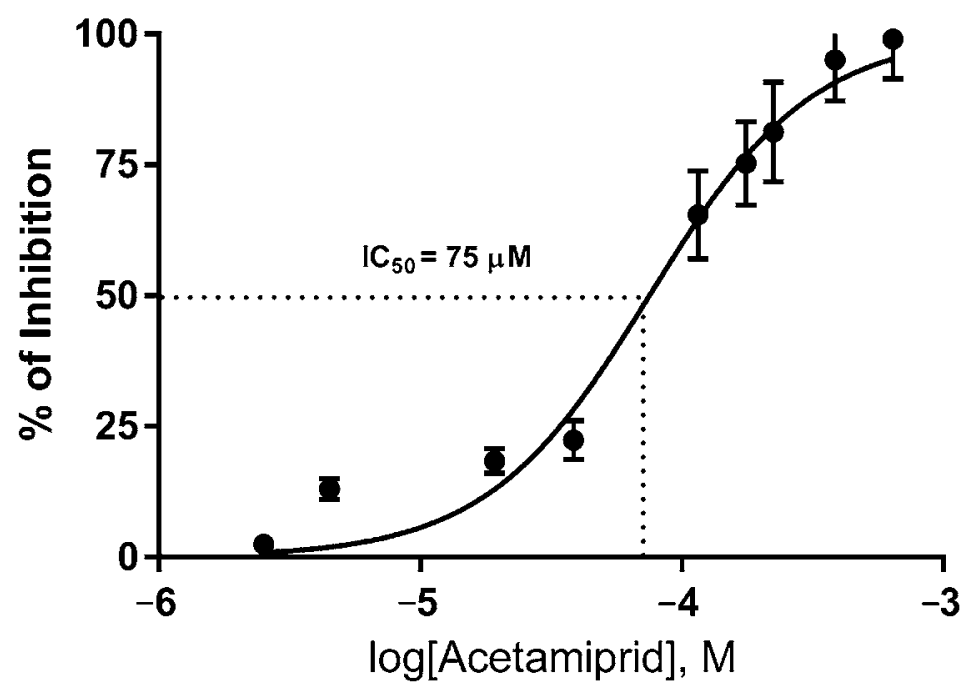

B

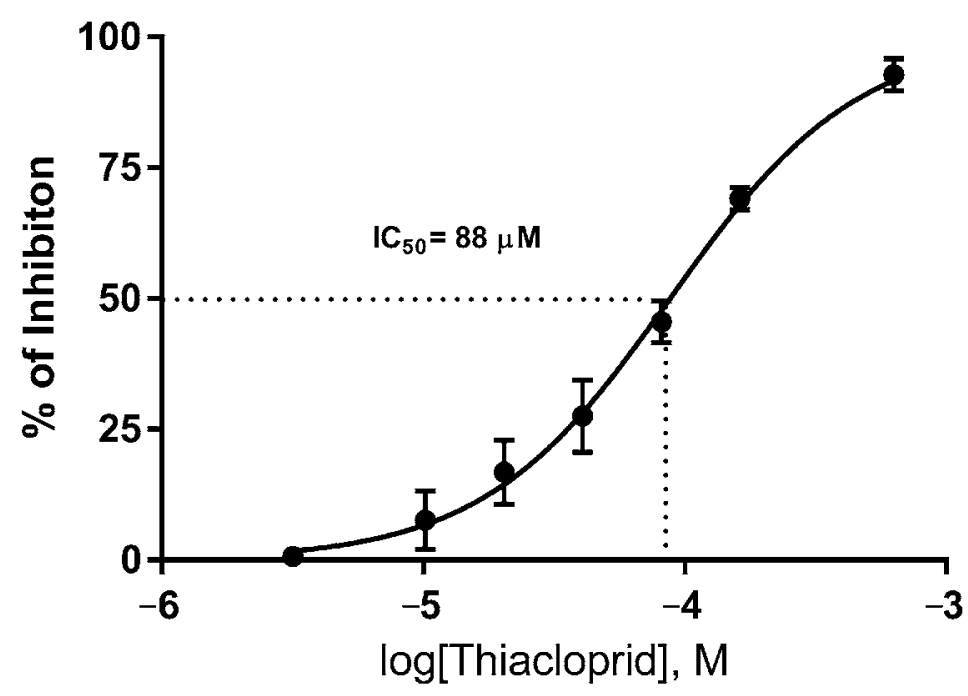

Fig. 3. Inhibition of AChE by ACT and TIA, showing the relative enzyme activity as a function of the inhibitor concentration in semi-logarithmic scale. $\mathrm{A}-$ Sigmoidal $\mathrm{IC}_{50}$ curves against inhibitor concentrations of $\mathrm{ACT}$. B - $\mathrm{IC}_{50}$ curves against inhibitor concentrations of TIA 
A

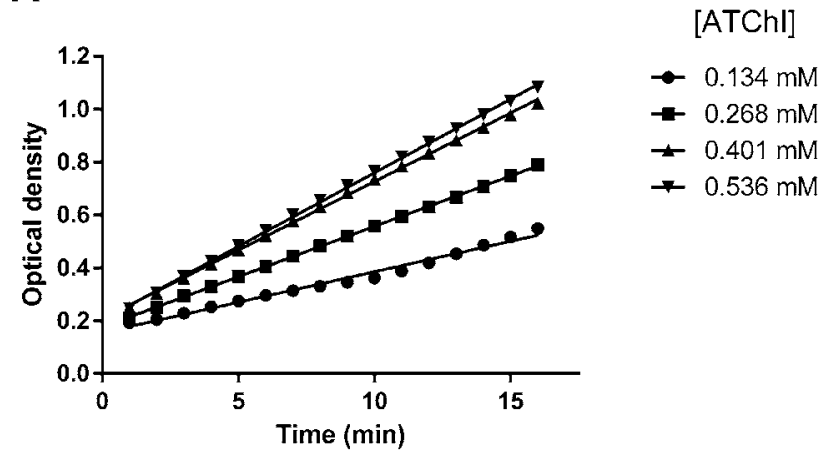

B

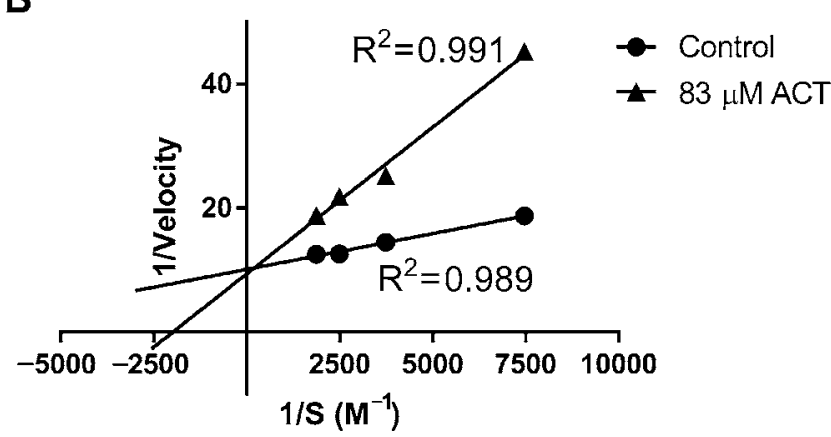

C

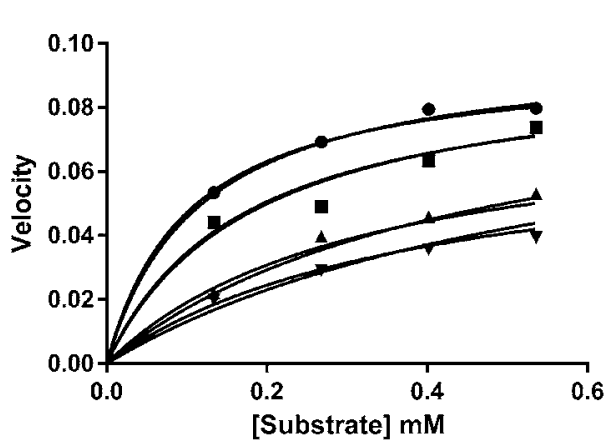

[Neonicotinoid]

$\rightarrow 0$

$\rightarrow 19 \mu \mathrm{M} \mathrm{ACT}$

- $83 \mu \mathrm{MACT}$

$\rightarrow 125 \mu \mathrm{MACT}$

Fig. 4. Steady state velocity for $\mathrm{AChE}$ in the presence of $\mathrm{ACT}$ at varying concentrations. $\mathrm{A}$ - Original traces recorded in the presence of four concentrations of ATChI. B - Steady state inhibition by ACT of hydrolysis of ATChI catalyzed by AChE. Lineweaver-Burk reciprocal plots of initial velocity and different substrate concentrations (1.85 mM-7.5 mM stock of ACThI) showing competitive type of inhibition. The data were extrapolated to cross the Y-axis. $\mathrm{R}^{2}$ values are indicated beside each line. $\mathrm{C}-$ Substratevelocity curves in the presence of three concentrations of neonicotinoid (control, 19, 83 and $125 \mu \mathrm{M}$ ACT) showing competitive type of inhibition. The concentrations of ACT are labeled, solid line shows the result of non-linear fitting 
ACT concentration (approximately the $\mathrm{IC}_{50}$ value). Solid lines represent the fitting of least-squares analysis, as shown in Fig. 4B. The directions of curves, no change of $V_{\max }$, and the changes of the slopes corresponding to a competitive mechanism. The correlation coefficients, $\mathrm{R}^{2}$, (marked in Fig. 4B) are quite high in all graphs, which confirm the precision of the assay.

Steady state velocity for $\mathrm{AChE}$ in the presence of $\mathrm{ACT}$ at varying concentrations was fitted by a non-linear regression (Fig. 4C). To get a value of alpha, mixed inhibition was assumed first (Table 2 mixed model). High value of alpha is a signal of competitive mechanism because when alpha is very large, binding of the inhibitor prevents binding of the substrate and the mixed-model becomes identical to competitive inhibition. The results of parameters, assuming a competitive interaction, are collected in Table 2 (competitive model). Half-maximal velocity is reached at 0.102 mM ATChI, inhibition constant is calculated as $K_{\mathrm{i}}=24.3 \mu \mathrm{M}$.

Table 2

Sumary of parameters collected by kinetic analysis of AChE inhibition by ACT

\begin{tabular}{|c|c|c|c|}
\hline Acetamiprid & & Std error & $95 \%$ confidence intervals \\
\hline \multicolumn{4}{|c|}{ Mixed model } \\
\hline Alpha & 10.15 & 11.22 & \\
\hline$V_{\max }$ & 0.0986 & 0.0061 & $0.0854-0.111$ \\
\hline$K_{\mathrm{i}}(\mu \mathrm{M})$ & 34.72 & 11.99 & \\
\hline$K_{\mathrm{m}}(\mathrm{mM})$ & 0.1161 & 0.0261 & $0.0591-0.173$ \\
\hline \multicolumn{4}{|c|}{ Competitive model } \\
\hline$V_{\max }$ & 0.0955 & 0.00525 & $0.084-0.107$ \\
\hline$K_{\mathrm{i}}(\mu \mathrm{M})$ & 24.34 & 4.586 & $14.43-34.24$ \\
\hline$K_{\mathrm{m}}(\mathrm{mM})$ & 0.1027 & 0.02245 & $0.054-0.152$ \\
\hline
\end{tabular}

\section{DISCUSSION}

Neonicotinoids, unlike pyretroids, are not generally established as AChE enzyme inhibitors, but some recent data also suggest their potency to modulate $\mathrm{AChE}$ activity. Changes in learning ability has been observed in honeybees exposed to some $\mathrm{AChE}$ inhibitors. A significant inhibition in AChE activity has been revealed after treatment of the German cockroach with neonicotinoid ACT for 24, 48 and 72 hours [19]. In contrary, application of neonicotinoids to caged bees resulted in opposite effects, elevated the activity of $\mathrm{AChE}$, and decreased the survival of bees [4]. The authors presumed that because neonicotinoids occupy the binding-site of acetylcholine, this neurotransmitter was accumulated in the synapses and stimulated the AChE enzyme. Thus, indirect effects of the potent neuromodulator neonicotinoids may also be involved, as the imbalanced functioning of the cholinergic system may trigger some compensatory mechanisms, including AChE activity modulation [20]. 
Our results demonstrated that ACT, CLO, TIA and TMX are all capable of blocking the activity of AChE in vitro in a concentration dependent manner. ACT, TIA has a rather surprisingly strong blocking effect on $\mathrm{AChE}$, and its potency $\left(\mathrm{IC}_{50}=75.2 \mu \mathrm{M}\right.$ and $85.4 \mu \mathrm{M}$ ) is close to the $\mathrm{LD}_{50}$ of well-known organophosphate insecticides like diazinon or carbaryl both acting as AChE inhibitors in vitro [4]. Some neonicotinoids acts as a partial agonist of nAChRs in cultured honeybee Kenyon Cells, exhibiting an $\mathrm{EC}_{50}$ value of $25 \mu \mathrm{M}$ [6]. These values are near or even lower than those of insecticides commonly applied in field sprays for pest control. We also found that ACT exhibited much higher potency of AChE inhibition than TMX and CLO, probably due to its cyano-substituted structure. Due to the difference in efficacy, the kinetic analysis of binding of ACT with AChE was studied in detail. An analysis of LineweaverBurk reciprocal plots based on initial velocity and different substrate concentrations showed mixed type of inhibition with same $V_{\max }$ and increased $K_{\max }$ in the presence of ACT. The directions of curves (lines that converge at the $y$-axis) and the changes of the slopes clearly correspond to a competitive mechanism. An analysis of Michaelis-Menten plots based on initial velocity and substrate concentration for ACT showed competitive type of inhibition. The very large alpha value suggests that binding of the substrate is prevented by ACT [5].

Neonicotinoids tested on the intact animals affect the mobility and memory of bees, and several lethal and sub-lethal effects have also been reviewed [3]. To find a primary target is not an easy task, partly because the pollinators, including honeybees, may be exposed simultaneously to other contaminants as well, and the effect of neonicotinoids for example can be enhanced in vivo by sub-lethal doses of herbicides [4] or AChE inhibiting organophosphate miticides [20, 29]. Moreover, synergistic effects in the toxicity of neonicotinoids to bees with fungicide active ingredients e.g. thiamethoxam due to some yet unknown mechanism have also been reported $[10,16,21$, 30]. The guttated water of seed-dressed plants might be a further source of contamination to bees [22]. In laboratory studies, the activity of AChE increased in surviving bees and decreased in dead bees indicating a correlation between the level of $\mathrm{AChE}$ activity and the fitness of exposed honeybees [2]. The low value of inhibition constant $\left(K_{\mathrm{i}}=24.3 \mu \mathrm{M}\right)$ of ACT found in our in vitro experiments indicates its strong binding to $\mathrm{AChE}$, the concentration range are encountered by honeybees too [3].

The $\mathrm{IC}_{50}$ values for CLO $(160 \mu \mathrm{M}=40 \mathrm{mg} / \mathrm{l})$ and TMX $\left(\mathrm{IC}_{50}=414 \mu \mathrm{M}=120\right.$ $\mathrm{mg} / \mathrm{l}$ ) are much higher, however Tapparo et al. [24] undertook studies with guttation drops of corn seedlings obtained from coated seed, in which they found up to 102 $\mathrm{mg} / \mathrm{l} \mathrm{CLO}$ and $146 \mathrm{mg} / \mathrm{l}$ for TMX. Similar data were reported earlier, when CLO and TMX concentrations peaked above $100 \mathrm{mg} / \mathrm{l}$, and guttation drops from neonicotinoid-coated seeds contained amounts constantly higher than $10 \mathrm{mg} / 1$ [11]. Comparing these data we can conclude, that CLO and TMX appearing in this concentration range can also represent a substantial environmental risk primary to pollinator organisms.

There seems to be a contradiction between toxicity data (ACT versus TMX) when comparing our results with literary data. We found ACT to be more effective than TMX (by threshold and $\mathrm{IC}_{50}$ concentration values), while contact $\mathrm{LD}_{50}$ values on bees 
resulted in magnitudes stronger toxicity of TMX than ACT [13]. However, behavior and physiology of bees are more affected by ACT than by TMX. Our data suggest that CLO, TMX and ACT, TIA according their chemical structures, belong to two subgroups acting differently as antagonists of $\mathrm{AChE}$. These results are in agreement with behavioral studies conducted on bees [8], and can explain the lack of the effect of TMX on their learning performance and locomotor activity. One cannot forget, however, that $\mathrm{AChE}$ activity measured in vitro in our experiments is just one of the possible targets of the neonicotinoids, while intact animal (in vivo) experiments affect the whole organisms (and probably a whole set of partly unknown target mechanisms).

\section{CONCLUSIONS}

Our results suggest that the neuronal AChE enzyme is among the direct targets of the neonicotinoid type insecticides and that their AChE inhibitory effects very likely contribute to toxic effects on the whole exposed animal. Therefore, to assess the toxic effects of this type of insecticide in vitro measurement of AChE activity would also contribute to toxicity tests. It is also concluded that neonicotinoids are not a uniform group regarding the blocking of the AChE, so chemically distinct neonicotinoids may affect different neuronal mechanisms. Thus, further investigations are required in order to find additional targets and establish the exact inhibition mechanisms in vivo.

\section{ACKNOWLEDGMENTS}

We thank to Dr. András Ács for his technical help of inhibitor studies. This project was supported by the Hungarian Scientific Research Fund (OTKA K-112712, K-112978).

\section{REFERENCES}

1. Anhalt, J. C., Moorman, T. B., Koskinen, W. C. (2008) Degradation and sorption of imidacloprid in dissimilar surface and subsurface soils. J. Environ. Sci. Health B 43, 207-213.

2. Badiou, A., Meled, M., Belzunces, L. P. (2008) Honeybee Apis mellifera acetylcholinesterase a biomarker to detect deltamethrin exposure. Ecotoxicol. Environ. Saf. 69, 246-253.

3. Blacquiere, T., Smagghe, G., van Gestel, C. A., Mommaerts, V. (2012) Neonicotinoids in bees: a review on concentrations, side-effects and risk assessment. Ecotoxicology 21, 973-992.

4. Boily, M., Sarrasin, B., Deblois, C., Aras, P., Chagnon, M. (2013) Acetylcholinesterase in honey bees (Apis mellifera) exposed to neonicotinoids, atrazine and glyphosate: laboratory and field experiments. Environ. Sci. Pollut. Res. Int. 20, 5603-5614.

5. Cortes, A., Cascante, M., Cardenas, M. L., Cornish-Bowden, A. (2001) Relationships between inhibition constants, inhibitor concentrations for $50 \%$ inhibition and types of inhibition: new ways of analysing data. Biochem. J. 357, 263-268.

6. Deglise, P., Grunewald, B., Gauthier, M. (2002) The insecticide imidacloprid is a partial agonist of the nicotinic receptor of honeybee Kenyon cells. Neurosci. Lett. 321, 13-16. 
7. DeLorenzo, M. E., Thompson, B., Cooper, E., Moore, J., Fulton, M. H. (2012) A long-term monitoring study of chlorophyll, microbial contaminants, and pesticides in a coastal residential stormwater pond and its adjacent tidal creek. Environ. Monit. Assess. 184, 343-359.

8. El Hassani, A. K., Dacher, M., Gary, V., Lambin, M., Gauthier, M., Armengaud, C. (2008) Effects of sublethal doses of acetamiprid and thiamethoxam on the behavior of the honeybee (Apis mellifera). Arch. Environ. Contam. Toxicol. 54, 653-661.

9. Ellman, G. L., Courtney, K. D., Andres, V., Jr., Feather-Stone, R. M. (1961) A new and rapid colorimetric determination of acetylcholinesterase activity. Biochem. Pharmacol. 7, 88-95.

10. Elston, C., Thompson, H. M., Walters, K. F. A. (2013) Sub-lethal effects of thiamethoxam, a neonicotinoid pesticide, and propiconazole, a DMI fungicide, on colony initiation in bumblebee (Bombus terrestris) micro-colonies. Apidologie 44, 563-574.

11. Girolami, V., Mazzon, L., Squartini, A., Mori, N., Marzaro, M., Di Bernardo, A., Greatti, M., Giorio, C., Tapparo, A. (2009) Translocation of neonicotinoid insecticides from coated seeds to seedling guttation drops: a novel way of intoxication for bees. J. Econ. Entomol. 102, 1808-1815.

12. Goulson, D. (2013) REVIEW: An overview of the environmental risks posed by neonicotinoid insecticides. J. Appl. Ecol. 50, 977-987.

13. Iwasa, T., Motoyama, N., Ambrose, J. T., Roe, R. M. (2004) Mechanism for the differential toxicity of neonicotinoid insecticides in the honey bee, Apis mellifera. Crop Protection 23, 371-378.

14. Jeschke, P., Nauen, R. (2008) Neonicotinoids-from zero to hero in insecticide chemistry. Pest Manag. Sci. 64, 1084-1098.

15. Jeschke, P., Nauen, R., Schindler, M., Elbert, A. (2011) Overview of the status and global strategy for neonicotinoids. J. Agric. Food Chem. 59, 2897-2908.

16. Krupke, C. H., Hunt, G. J., Eitzer, B. D., Andino, G., Given, K. (2012) Multiple Routes of Pesticide Exposure for Honey Bees Living Near Agricultural Fields. PLoS One 7.

17. Lamers, M., Anyusheva, M., La, N., Nguyen, V. V., Streck, T. (2011) Pesticide Pollution in Surfaceand Groundwater by Paddy Rice Cultivation: A Case Study from Northern Vietnam (vol 39, pg 356 2011). Clean-Soil Air Water 39, 508-508.

18. Matsuda, K., Buckingham, S. D., Kleier, D., Rauh, J. J., Grauso, M., Sattelle, D. B. (2001) Neonicotinoids: insecticides acting on insect nicotinic acetylcholine receptors. Trends Pharmacol. Sci. 22, 573-580.

19. Morakchi, S., Maiza, A., Farine, P., Aribi, N., Soltani, N. (2005) Effects of a neonicotinoid insecticide (acetamiprid) on acetylcholinesterase activity and cuticular hydrocarbons profil in German cockroaches. Commun. Agric. Appl. Biol. Sci. 70, 843-848.

20. Palmer, M. J., Moffat, C., Saranzewa, N., Harvey, J., Wright, G. A., Connolly, C. N. (2013) Cholinergic pesticides cause mushroom body neuronal inactivation in honeybees. Nat. Commun. 4.

21. Pettis, J. S., Lichtenberg, E. M., Andree, M., Stitzinger, J., Rose, R., Vanengelsdorp, D. (2013) Crop Pollination Exposes Honey Bees to Pesticides Which Alters Their Susceptibility to the Gut Pathogen Nosema ceranae. PLoS One 8.

22. Reetz, J. E., Zuhlke, S., Spiteller, M., Wallner, K. (2011) Neonicotinoid insecticides translocated in guttated droplets of seed-treated maize and wheat: a threat to honeybees? Apidologie 42, 596-606.

23. Starner, K., Goh, K. S. (2012) Detections of the neonicotinoid insecticide imidacloprid in surface waters of three agricultural regions of California, USA, 2010-2011. Bull. Environ. Contam. Toxicol. $88,316-321$.

24. Tapparo, A., Giorio, C., Marzaro, M., Marton, D., Solda, L., Girolami, V. (2011) Rapid analysis of neonicotinoid insecticides in guttation drops of corn seedlings obtained from coated seeds. J. Environ. Monit. 13, 1564-1568

25. Tomizawa, M., Casida, J. E. (2003) Selective toxicity of neonicotinoids attributable to specificity of insect and mammalian nicotinic receptors. Annu. Rev. Entomol. 48, 339-364.

26. Tomizawa, M., Casida, J. E. (2005) Neonicotinoid insecticide toxicology: Mechanisms of selective action. Annu. Rev. Pharmacol. Toxicol. 45, 247-267. 
27. van der Sluijs, J. P., Simon-Delso, N., Goulson, D., Maxim, L., Bonmatin, J. M., Belzunces, L. P. (2013) Neonicotinoids, bee disorders and the sustainability of pollinator services. Curr. Opin. Env. Sust. 5, 293-305.

28. van Engelsdorp, D., Evans, J. D., Saegerman, C., Mullin, C., Haubruge, E., Nguyen, B. K., Frazier, M., Frazier, J., Cox-Foster, D., Chen, Y. P., Underwood, R., Tarpy, D. R., Pettis, J. S. (2009) Colony Collapse Disorder: A Descriptive Study. PLoS One 4.

29. Williamson, S. M., Wright, G. A. (2013) Exposure to multiple cholinergic pesticides impairs olfactory learning and memory in honeybees. J. Exp. Biol. 216, 1799-1807.

30. Wu, J. Y., Smart, M. D., Anelli, C. M., Sheppard, W. S. (2012) Honey bees (Apis mellifera) reared in brood combs containing high levels of pesticide residues exhibit increased susceptibility to Nosema (Microsporidia) infection. J. Invert. Pathol. 109, 326-329. 